\title{
Numerical Study on Influence of Impacts from Environmental Factor on CO Concentration in Tunnel with Longitudinal ventilation
}

\author{
Yachao $\mathrm{LI}^{1, \text { a }}$, Liang $\mathrm{YI}^{2, \mathrm{~b}}$, Shaohui $\mathrm{CHEN}^{3}$ \\ ${ }^{1}$ School of Civil Engineering, Central South University, Changsha, Hunan, China, 410075, China \\ ${ }^{2}$ School of Civil Engineering, Central South University, Changsha, Hunan, China, 410075, China \\ ${ }^{3}$ Headquarters of Mazhao Highway project, Yunnan, China, China \\ aemail: 234489739@qq.com, bemail:5148277@qq.com
}

Keywords: tunnel; CO concentration; FLUENT; numerical simulation; longitudinal ventilation

\begin{abstract}
The impacts from different environmental factors on CO concentration are studied based on FLUENT numerical simulation. Under different wind velocities, environmental temperatures, and super hydrostatic difference, the distribution of CO concentration inside the tunnel is analyzed. The result is that there is large impact from the environmental velocity and temperature on the concentration of CO inside the tunnel, but slightly influence from the super hydrostatic difference.
\end{abstract}

\section{Introduction}

With the continuous growth of urban traffic, the tunnel construction has become a means to relieve urban traffic, apart from the function of crossing mountains and oceans. Not only the number of tunnels is increasing, but also the length. For relatively long road tunnels, their high energy consumption and difficulty on management makes it a research focus on the tunnel ventilation. Tunnel ventilation is to remove the emission pollutants in time and keep them down the allowed figure, which can ensure the normal running conditions. The pollutants in tunnel include $\mathrm{CO}, \mathrm{NO}_{\mathrm{x}}$, flue gas, and so on. The distribution of $\mathrm{CO}$ inside the tunnel is similar to the cases of other gas. So, the distribution regularity of $\mathrm{CO}$ concentration is used to be representative. In the ventilation system of the road tunnel, the environmental factors can positively influence and facilitate the ventilation, which can save the operation costs and improve the economic efficiency.

The research made a tunnel simulation object to be a 3D simplified model. With steady state calculation, the ventilation processes under different environments and conditions have been analyzed, and the impacts from environmental factors have been studied.

\section{NUMERICAL SIMULATION AND COMPUTATION MODEL}

The vehicle gas diffusion appears to be spatial distribution, so the flow of gas diffusion is multi-component and 3D unsteady. Real simulation and calculation is very difficult, so it is necessary to make some simplification and assumptions to establish a physical and mathematical model for actual problems in research. In numerical calculation, mainly considering the diffusion of $\mathrm{CO}$ in the air, the governing equations and boundary conditions are determined by the physical model, and then the mathematical model can be established. Some factors should be considered when the physical model is established: the spatial dimensionality, the factor of time, the flow pattern, the boundary condition, and so on. So, to facilitate the calculation, there are some assumptions:

(1) The flow and transfer of CO in the tunnel is steady .

(2) The air in the tunnel is incompressible.

(3) No air leakage points except the air outlets and the exits.

(4) The CO content in the vehicle gas is the only considerable factor.

(5) gnore the disturbance to the flow from the vehicles and other objects in the tunnel. 


\section{Governing equations}

The distribution space of $\mathrm{CO}$ in the tunnel is very extensive, and can be nearly considered as the incompressible fluid. The study of its flow and diffusion is in the field of fluid mechanics. The governing equation covers the conservation of mass, the conservation of momentum, the conservation of energy, the composition equation (the concentration equation ), and so on.

The general form of the governing equation calculated with the FLUENT is:

$$
\frac{\partial(\rho x)}{\nabla \partial t}+\operatorname{div}\left(\rho \vec{u} x-F_{x} \nabla x\right)=S_{x}
$$

where: $X=$ unknown variable, represented the temperature, speed, pressure, component concentration, enthalpy, and so on; $\rho$ = density; $t$ =time; $\overrightarrow{\boldsymbol{u}}=$ velocity vector; $F_{X}=$ diffusion term; $S_{X}=$ source term.

In the simulation of the air flow field in the tunnel, the turbulence effect should be under the standard $k-\varepsilon$ Turbulent Model, owing to the successful computation in fluid dynamics simulation based on the Reynolds Average Navier-Stokes (RANS). The standard $k-\varepsilon$ Turbulent Model has been largely tested in engineering applications with its high precision. Besides, compared to other models like the large eddy simulation, the computational amount is relatively low.

\section{Numerical method}

To solve the differential equation above, the finite volume method (FVM) has been applied to do integral- discretization with the governing equation on micro units. The pressure term and the speed term are coupled by the equation set under the SIMPLE algorithm. The discretization to the convection terms are solved by second-order upwind scheme, and the diffusion terms have second order accuracy.

\section{Physical model}

Based on the actual dimension of the tunnel, in this simulation, the tunnel length is set $2070 \mathrm{~m}$, with its longitudinal slope $2.78 \%$, as shown in Figure 1 . The aocs-section of the tunnel is shown in Figure 1.

The meshing of the computation model is hexahedral structured mesh arrangement. After mesh independent analysis, the amount of mesh is 1549762, the minimum volume of the mesh is $3.985218 \mathrm{e}-03 \mathrm{~m}^{3}$, and the maximum volume is $4.848584 \mathrm{e}-01 \mathrm{~m}^{3}$.

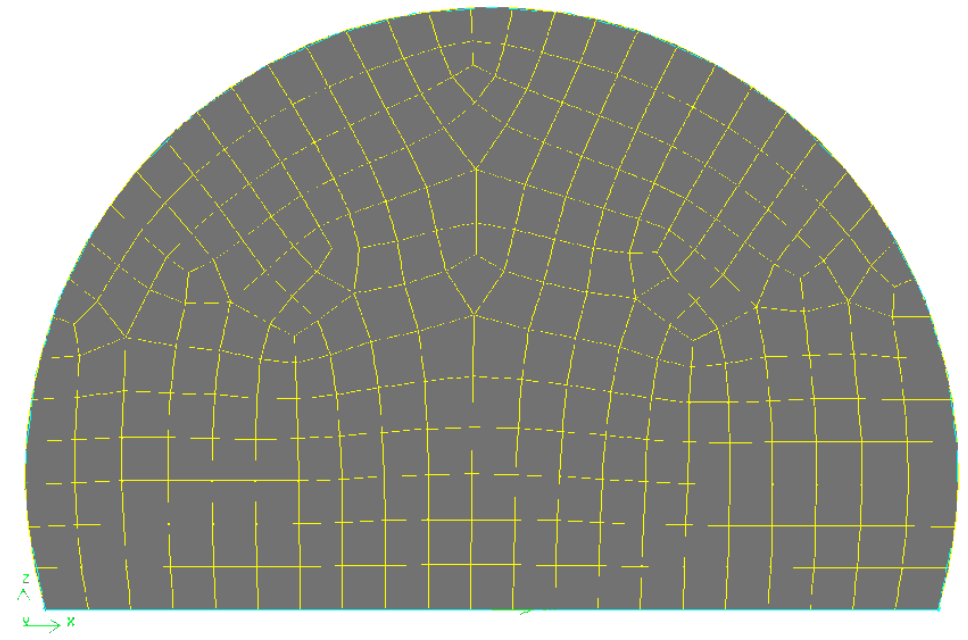

Figure 1. Tunnel model

\section{Parameters}

The numerical calculation is valid in the limited region, so there should be boundary conditions for the region. The tunnel walls are the solid surface, and the parameters in the function for the solid 
surface are based on its roughness. The tunnel entrance is set as the velocity boundary condition, and the exit is the pressure boundary condition. The traffic wind velocity is $7.64 \mathrm{~m} / \mathrm{s}$. The bottom of the tunnel is considered as the emission source of the pollutants, and is set as the flux boundary condition. Along the tunnel, the emission of CO is $0.024 \mathrm{~m}^{3} / \mathrm{s}$, and temperature is $400^{\circ} \mathrm{C}$.

Table 1. Condition setting

\begin{tabular}{lllll}
\hline Number & $\operatorname{vr}(\mathrm{m} / \mathrm{s})$ & $\mathrm{T} 0\left({ }^{\circ} \mathrm{C}\right)$ & $\mathrm{Tw}\left({ }^{\circ} \mathrm{C}\right)$ & $\Delta \mathrm{P}(\mathrm{Pa})$ \\
\hline A1 & 1 & & & \\
A 2 & 2 & 15 & 20 & 0 \\
A 3 & 3 & & & \\
A 4 & 4 & 0 & & \\
A 5 & 5 & 5 & 20 & 0 \\
\hline B1 & & 10 & & \\
B2 & 20 & & 0 \\
B3 & 3 & 25 & & 25 \\
B4 & & & & 50 \\
B5 & & 15 & & 75 \\
\hline C1 & & & \\
C2 & & & & 100 \\
C3 & & & & \\
C4 & & & & \\
C5 & & & & \\
\hline
\end{tabular}

Under different wind velocities at entrance, environmental temperatures, and the super hydrostatic difference in the tunnel, the situations of $\mathrm{CO}$ concentration field are respectively considered. As in the Table 1, 15 groups of working condition are set, where $v_{r}$ is the wind velocity at entrance, $T_{0}$ is the environmental temperature, $T_{w}$ is the temperature of the tunnel walls, and $\Delta P$ is the super hydrostatic difference.

\section{CALCULATION RESULTS AND ANALYSIS}

With the coupling between the pressure and velocity from the software Fluent, SIMPLE algorithm is to improve the precision. After the initialization of the system, iteration begins. With the satisfying solution after convergent iteration of error, the ventilation effect is simulated out.

\section{Impacts on ventilation effect from Different Wind Velocities at Entrance}

With different wind velocities at entrance of $1 \mathrm{~m} / \mathrm{s}, 2 \mathrm{~m} / \mathrm{s}, 3 \mathrm{~m} / \mathrm{s}, 4 \mathrm{~m} / \mathrm{s}, 5 \mathrm{~m} / \mathrm{s}$, the simulation result is shown as figure 2: the concentration of $\mathrm{CO}$ increases from the entrance to the exit inside the tunnel.

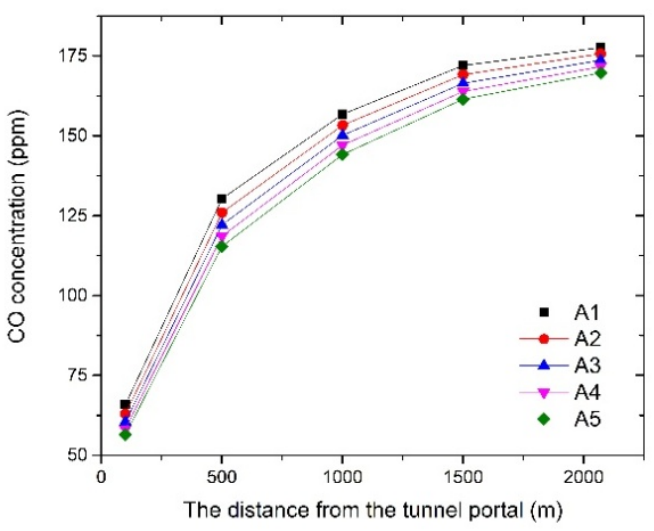

Figure 2. Distribution of the CO concentration under different wind velocities

From Figure 2, the distribution of the CO concentration is influenced by both the traffic wind velocity and the environmental wind velocity. When the environmental wind velocity increases 
from $1 \mathrm{~m} / \mathrm{s}$ to $5 \mathrm{~m} / \mathrm{s}$, the CO concentration decreases. From the working condition A1 to A5, the average concentration of $\mathrm{CO}$ at the exit are: 177.6ppm, 175.7ppm, 173.7ppm, 171.6ppm and 169.7ppm.

\section{Impacts on ventilation effect from different environmental temperatures}

In temperature of $0{ }^{\circ} \mathrm{C}, 5^{\circ} \mathrm{C}, 10^{\circ} \mathrm{C}, 15^{\circ} \mathrm{C}, 20^{\circ} \mathrm{C}$ and $25^{\circ} \mathrm{C}$, the distrubution of $\mathrm{CO}$ concentration field is simulated, and the result is shown in Figure 3: the concentration of CO increases from the entrance to the exit inside the tunnel.

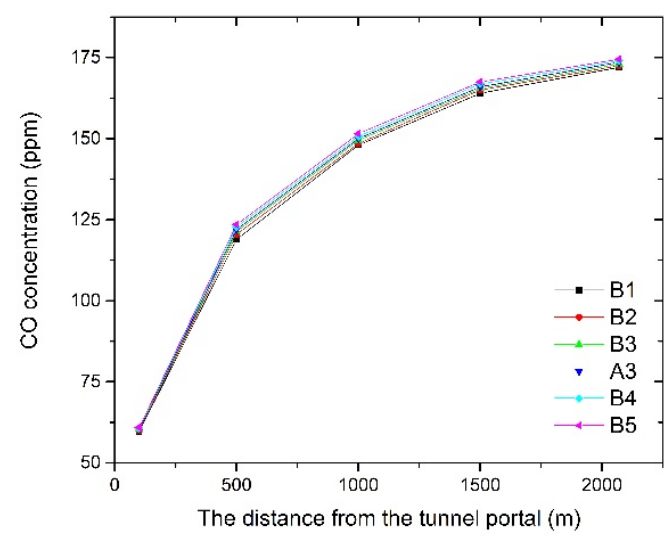

Figure 3. Distribution of the CO concentration under different temperatures

From the Figure 3, owing to the stack effect, the $\mathrm{CO}$ concentration increases as the temperature climbs. When the temperature climbs from $0{ }^{\circ} \mathrm{C}$ to $25^{\circ} \mathrm{Cinside}$ the tunnel, the concentration of $\mathrm{CO}$ increases along with the temperature. From $0{ }^{\circ} \mathrm{C}$ to $25^{\circ} \mathrm{C}$, the average concentration of Co at the exit of the tunnel are: 171.9ppm, 172.5ppm, 173.1ppm, 173.6ppm, 174.0ppm, 174.6ppm.

\section{Impacts on ventilation effect from different super hydrostatic differences}

Under different super hydrostatic differences of $0 \mathrm{~Pa}, 25 \mathrm{~Pa}, 50 \mathrm{~Pa}, 75 \mathrm{~Pa}$, and $100 \mathrm{~Pa}$ inside the tunnel, the distributuion of the $\mathrm{CO}$ concentration field is simulated. The result is shown in Figure 4, the concentration of $\mathrm{CO}$ increases from the entrance to the exit inside the tunnel.

From Figure 3, the concentration of CO in the tunnel is largely influenced by the traffic wind velocity, and slightly influence by the super hydrostatic difference. Under different super hydrostatic differences, there is little variation on the concentration of CO. When the super hydrostatic differences changes from $0 \mathrm{~Pa}$ to $100 \mathrm{~Pa}$, the average concentration of $\mathrm{CO}$ at the exit are: 179.16ppm, 179.17ppm, 179.19ppm, 179.17ppm, 179.34ppm.

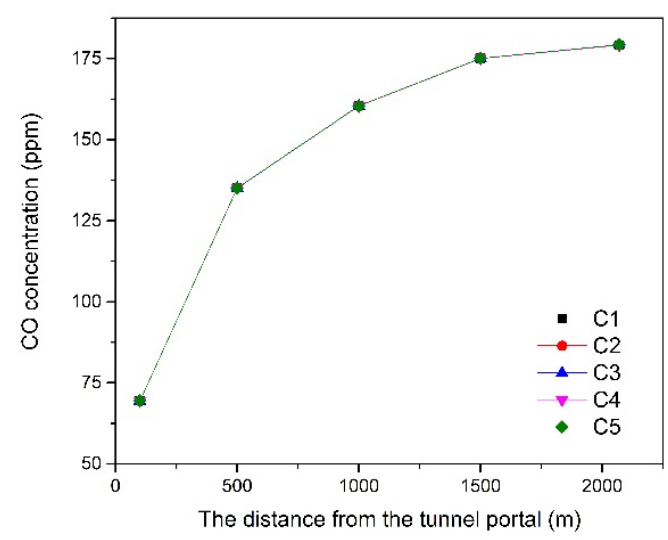

Figure 4. Distribution of the CO concentration under different super hydrostatic differences 


\section{Conclusion}

Distribution of exhaust emissions inside a tunnel was analyzed with FLUENT numerical simulation the following condition can be drawn.

Under different velocities at the entrance of the tunnel, the concentration of CO inside the tunnel increases as the velocity increases.

When the temperature difference between inside and outside of the tunnel is bigger, the chimney effect is more bovious. The concentration of CO in the tunnel was increased with the increase of the ambient temperature due to the effect of the chimney effect.

The concentration of CO inside the tunnel is largely influenced by the traffic wind velocity, and slightly influence by the super hydrostatic difference. Under different super hydrostatic difference, there is little change on the concentration of CO.

\section{References}

[1] Narendran N. \& K. Toomey. 2002. LED package Designs Tackle Lumen Depreciation Issues. Compound Semiconductor 8(1): 45-46.

[2] CIE. 2003 Guide on the limitation of the effects of obtrusive light from outdoor lighting installation. Technical Report Publication No. 150. Vienna: CIE.

[3] Zhang Xingjun, Chen Bin, Pang Yun \&Muqing Liu. 2010. LED Tunnel Lighting Uniformity Study. Control Engineering of China 17(9): 61-64.

[4] Gongxia Yang, Xudong Yang. 2006. Discomfort Glare and Discomfort Glare Rating. China Illuminating Engineer-ing Journal 17(2): 11-15.

[5] Yang Chao \& Wang Zhiwei. 2011. Research on the Application of in Tunnel Lighting Engineering. China Illuminating Engineering Journal 22(2): 60-66.

[6] Yan Guimei. 2008. Study on Relationship between Road tunnel Ventilation Lighting and Traffic safety. Chong-qing: Chongqing University.

[7] He Yiming, Wang Chonggui\& Liu Jinyu. 2010. Existing Problem and Energy-saving Technology of Highway Tunnel Lighting. Highway Construction and Maintenance (222):32-35. 